\title{
Urban Mangrove Wetlands, Challenges and its Conservation: Sri Lanka Perspectives
}

\author{
Mathiventhan, $\mathbf{T}^{*}$, Jayasingam, T, Umaramani, $M$ \\ Department of Botany, Eastern University, Sri Lanka
}

*Corresponding Author: Mathiventhan, T, Department of Botany, Eastern University, Sri Lanka

\begin{abstract}
Urban wetlands make cities livable in many important ways. They reduce flooding, replenish drinking water efficiently and cheaply, filter waste, serve a function by developing greater biodiversity, provide urban green spaces, and are a source of livelihoods. Mangroves are an intertidal ecosystem which are also very delicate and sensitive to changes in environment. Urban mangrove wetlands are rarely found and are reducing in recent past, locally and globally. The primary drivers of degradation and loss of urban mangrove wetlands are population growth and increasing economic development, infrastructure development, land conversion, water withdrawal, eutrophication and pollution, overharvesting and overexploitation, and the introduction of invasive alien species. Conservation of this urban mangrove wetland is a challenge for many reasons especially when focusing on the economic development and relevant activities.
\end{abstract}

Keywords: land conversion, public interest, policies, scientific planning.

\section{INTRODUCTION}

Wetlands could be two types namely natural and artificial. Natural wetlands include rivers, lakes, estuaries, swamps, tidal flats, coral reefs and mangroves. Artificial wetlands include artificially constructed canals, reservoirs, artificial lakes, rice fields and sewage treatment sites.

Urban wetlands are an important part of urban ecosystem, taking on important and irreplaceable ecological service function and cannot be substituted by other ecosystems, which in turn ensures sustainable development. Urban wetlands have different climatic characteristics than urban areas, and are different depending on the urban functional areas.

Compared with natural wetlands, urban wetlands also have their own unique characteristics, and has been severely damaged, especially with the acceleration of urbanization process. Urban wetlands have formed uneven distribution, small area, island wetland patches, due to the impact of urbanization, which increases the degree of fragmentation of habitats in wetlands [1]. Disaster, both natural and man-made, and development had caused not only decrease in mangrove ecosystem but also fragmented the available system which has a series of cumulative negative impacts over time, especially on urban wetlands. Human-driven activities often disconnect hydrological continuity of the mangrove wetland and will be challenging to the existence of the mangroves. It is estimated that at least 321 hectares of mangrove (about 15-20\% of the total) have been cleared around Batticaloa estuary over the past two decades [2].

\section{WHY URBAN WETLANDS ARE IMPORTANT?}

Urban wetlands provide a variety of benefits and services to the community. In addition to providing habitat for plants and animals, wetlands provide water storage, improve water quality and reduce pollution. Wetlands also protect against natural hazards, slowing floodwaters, reducing the risk of fire and protecting against erosion of river banks and coastlines. Wetlands and associated vegetation can provide a cooling effect to surrounding areas and also moderate strong winds. Wetlands can also contribute to the well-being of the community by acting as urban green spaces which provide aesthetic appeal, landscape diversity and recreational opportunities. They can also contribute to cultural heritage, spiritual values and day-to-day living of fishers who depend on it. Additionally, wetlands provide easily accessible educational and research opportunities to learn about the environment. 


\section{Sathurukondan, an Urban Wetland, Batticaloa Sri Lanka: Lesson Learned}

It is one of the urban wetlands (Figure 1), which had survived the war and the human exploitation for many decades but have been subject to much encroachment recently. These wetlands being around the main road had been cut for security reasons during the armed conflict between 1980-2006, which however had regenerated profusely to a patch with Rhizophora, and Sonneratia sp, bordering the lagoon with Avicennia and Excoecaria sp. at distances away from it with Acrostichum sp. There had been many studies on this wetland from visits of the University students each year to research study for by national and international candidates, and it is one of the most significant sites for Bird watching around Batticaloa which has been reported in many studies from 1993 to 2017 [3][4].
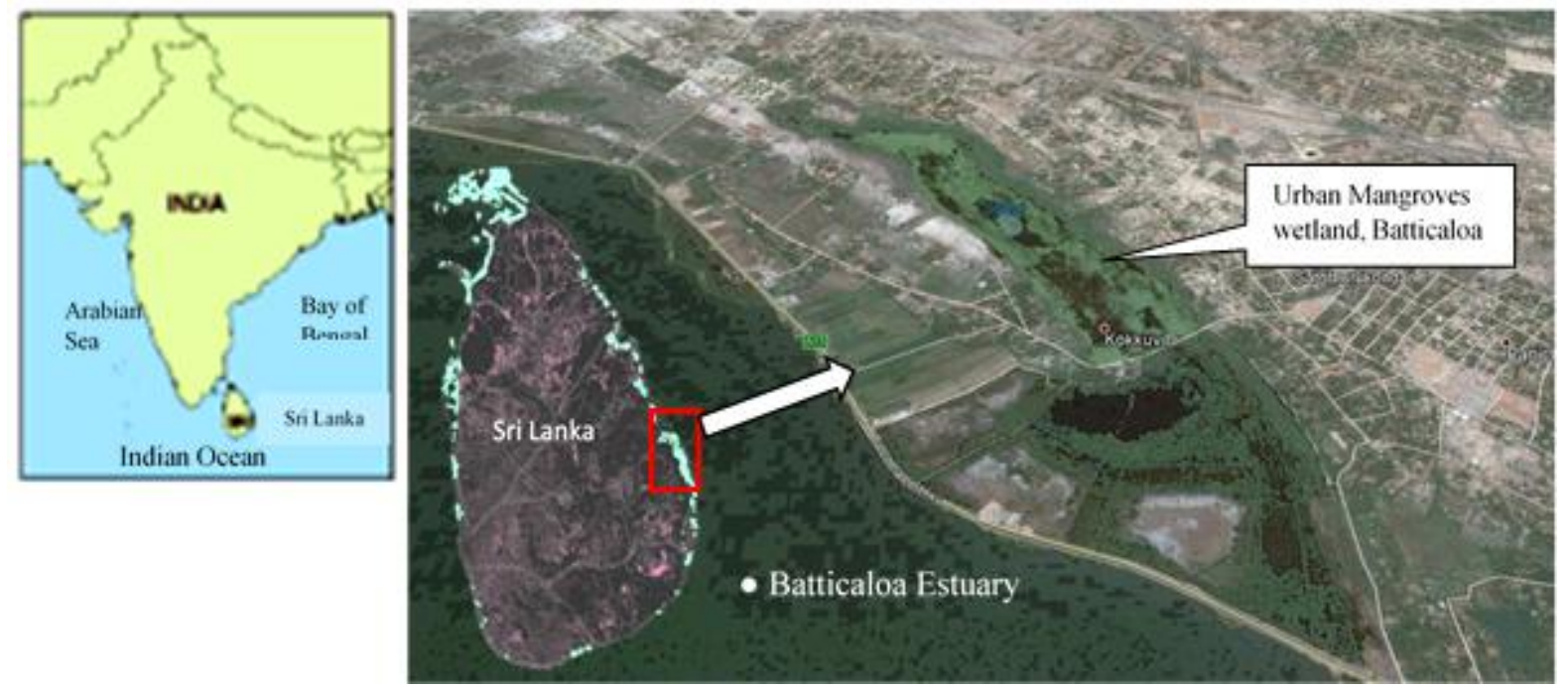

Figure1. Sri Lanka is an Island located in the Indian Ocean (left). Batticaloa on the east coast of Sri Lanka; Mangrove distribution found almost around the island (middle). Source: Hansen/UMD/Google/USGS/NASA, Mongabay Series: Global Forest Reporting Network. Mangroves pockets intermingled with the urban settings at Sathurukondan, Batticaloa, Sri Lanka - bordered with Batticaloa estuary on left side and urban settings on right side (right). Source: Google

Many have claims over some of the lands in the patch and also have undertaken filling of these land changing from its status as wetland even though, it borders the Batticaloa estuary and is situated in the banks of the estuary, getting flooded each time the estuary is flooded during the monsoon rains. It is the largest patch of mangroves around Batticaloa situated in an urban setup, which serves as the breeding grounds for the fisheries in lagoon and shelter for the avifauna in the region. The landward demarcation was easily made by the rows of Cerbera manghas (mangrove associate) in 1980s. It is expressed that the Indian army which patrolled in this area in 1987 had considered them as Mangoes and eaten them to be later hospitalized. Unfortunately, the entire rows of these trees are no more now.

Attempts were made for its conservation at many times: 1992 - declared as the protected site by the Government Agent (GA); 2002 - Batticaloa estuary and adjoining area are declared under FMA (Fisheries Management Areas) under section 31 of the FARA (Fisheries and Aquatic Resources Act); 2006 - Batticaloa estuary and the adjoin areas are declared as wetlands under the RAMSAR classification [5]; 2006 - Potential Special Area Management (SMA) site - [6]; 2016/2017- "Conserving wetlands around the lagoons (estuary) in the Batticaloa district" by the CCD (Coast Conservation Department).

Even though measures had been taken to conserve the wetland, it is facing many threats for its existence such as urban expansions and the correspondingly lower groundwater levels put pressure on wetland, encroachment, land filling and conversion, blocking water passage and illegal cutting and felling. Conversion of this urban mangrove wetland is the major issue (Figure 2) at present, which disconnects the continuity and affects the hydraulic dynamics of the wetland and leads flooding in the surrounding areas [7] each year, during rainy seasons, after 2011. 

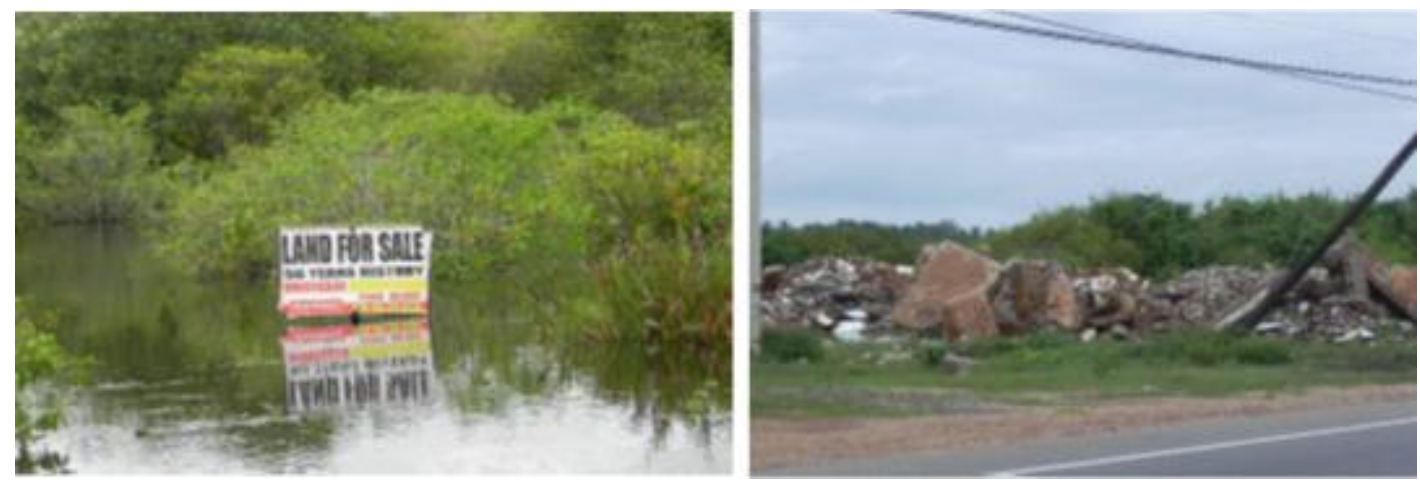

Figure2. Mangrove wetland subjected to human threat at Sathurukkondan, Batticaloa, 2016. The wet land exposed to sale by claiming as private land (left), and filling the wetland economic activities (right).

\section{Conservation}

An undisturbed urban (mangrove) wetland is a sign of good health because of its diversity of species, structural complexity, functional integration and resistance to external forces (resilience). When the disturbances are more than the resilient capacity of the wetland, then the health will deteriorate, the function will degrade, and thus affect the regional environment. Therefore, it is our obligation to conserve the valuable wetlands, especially the urban wetlands for future generation.

\subsection{Developing National Policy for Conservation and Sustainable Utilization of Urban Mangrove Wetlands/Ecosystems}

Some countries have the policy for mangroves and many others may not have it. It is a unique system governed neither by the rules of the wetlands not of the forest but has its own including for the habitat. Sri Lanka is developing one which is almost done. It is essential that definite policies are there for the conservation and management of mangroves as it is a very unique ecosystem neither a forest nor a wetland and lives in an environment that no other vegetation dare to survive.

\subsection{Study the Changes Regularly to Understand them and Manage them}

Scientists need to study changes for long term understanding. There are very few studies that had been long enough for such in the world like some of the forest or pasture systems.

\subsection{Conserving Tourism Value and Promote Wise use of Wetland}

Urban wetlands have potential tourism value in terms of bird watching, animal observation points and mangrove flora. The wetland could be modified for the above purpose by initiating forest walk, boat riding, leisure foods and drinks (Sonneratia sp.), photography, etc.

\subsection{Strengthening Scientific Procedures, Policies and Relevant Actions}

It is vital to avoid further degradation or loss of wetlands as a result of urban development or mitigate the impacts. Any residual impacts should be appropriately compensated such as wetland restoration and replantation. Involve local communities, including Indigenous people, on urban planning and wetland management is also a sustainable mode of management. Policies relevant to wetland conservation and management need to be strengthen in term of its application [8]. "A special problem in Sri Lanka was, and is, the fact that the responsibility for wetland management is divided among numerous institutions" .... "In all these institutions the level of knowledge and expertise is generally high, but unfortunately the cooperation between, or sometimes within, the various institutions are mostly limited or absent" [9]. Therefore, it is vital for a horizontal and vertical integration between Conservation Authorities, Development Authorities and Local communities.

\subsection{Integrated Urban Planning}

Wetland management should be integrated into the urban spatial planning and water resource management. This will avoid loss of wetland and its ecological niche. Urban planning should explicitly include wetlands as natural infrastructure for nature conservation, landscape planning and water management. 
If these fundamentals are violated or not seriously undertaken, we would soon not have any NATURE but only memories of them in near future. If we don't do what should be done today, tomorrow may never have a chance to even know that. Today would be yesterday for them.... a history.

\section{REFERENCES}

[1] Pengfei Ye, Xiaoying Hao, Yifei Cao. Analysis on ecological protection of urban wetlands. Natural Resources Conservation and Research, 1-7 (2018).

[2] NECCDEP. Batticaloa Lagoon Special Area Management Plan "BL SAM". Final. Pp. 125. January 2010. Eastern Province Integrated Coastal Resources Management Plan (EPICRMP) 2010-2013. The Green Blue Sunrise Plan. Anzdec Ltd., Resource Development Consultants. ADB LOAN 2027 SRI (SF): North East Coastal Community Development Project (NECCDEP), 125 pp (2010).

[3] Kishoran, S., Harris, J.M., Vinobaba, M., and Vinobaba, P. Bird diversity and threats to their habitat in Sathurukondan birding site in Batticaloa Sri Lanka. Journal of Agricultural Science and Technology A7, 123-128 (2017).

[4] Jonnson, M. Social-Ecological Resilience of Mangroves and Coastal Households in Batticaloa District, Sri Lanka. Master's Thesis, Norwegian University of Life Sciences, As, Norway, 124 pp (2017).

[5] EA, IUCN, IWMI. National Wetland Directory of Sri Lanka, 2006. The Central Environmental Authority (CEA), The World Conservation Union (IUCN) and the International Water Management Institute (IWMI), Colombo, Sri Lanka, 342 pp, (2006).

[6] CZMP. [(Part I Sec (I) GAZETTE EXRTAORDINARY OF THE DEMOCRATIC SOCIALIST REPUBLIC OF SRI LANKA, $58 \mathrm{pp}$ (2006).

[7] Mathiventhan, T. and Jayasingam, T. Impact of flood on Rhizophora plantation in Batticaloa, Sri Lanka. Journal of Medical and Bioengineering. Engineering and Technology Publishing (ETP, ISSN 2301-3796), (3)2:117-121(2014).

[8] CEA. National wetland policy and strategy. Ministry of Environment, Central Environmental Authority, 40 pp (2006).

[9] Van Zon, J.C.J. Wetland conservation and management in Sri Lanka: A status paper. In: Wetland Conservation in Sri Lanka, Proceedings of the National Symposium on Wetland Conservation and Management: Sri Lanka, 2-18 (2006).

Citation: Mathiventhan, T, Jayasingam, T, Umaramani, M, "Urban Mangrove Wetlands, Challenges and its Conservation: Sri Lanka Perspectives", International Journal of Research Studies in Biosciences (IJRSB), vol. 6, no. 3, pp. 23-26, 2018. http://dx.doi.org/10.20431/2349-0365.0603005

Copyright: () 2018 Authors. This is an open-access article distributed under the terms of the Creative Commons Attribution License, which permits unrestricted use, distribution, and reproduction in any medium, provided the original author and source are credited. 